\title{
Patients with Severe Asthma: Analysis of Future Risks
}

\author{
SAJIDA PARVEEN ${ }^{1}$, GHUFRAN ZAFAR ${ }^{2}$, RUKHSHANDA NOSHEEN ${ }^{3}$ \\ ${ }^{1}$ MBBS, Dera Ghazi Khan Medical College, DG Khan \\ ${ }^{2}$ MBBS, Hainan Medical University, China \\ ${ }^{3}$ MBBS, Govt. Khwaja Muhammad Safdar Medical College, Sialkot \\ Correspondence to Dr. Rukhshanda Nosheen Email: tamimrai18@gmail.com
}

\begin{abstract}
The upcoming severe health problems can be due to the asthmatic burdens. Severe asthma can lead to dangerous exacerbation and damage of pulmonary function. It can also affect medication-related problems for example steroids. In routine practice, the risk of asthma is not easily detectable. The present tools for the measurement and diagnosis of asthma and asthma-related morbidity cannot surely predict the upcoming risks of morbidity due to medication. The article reviews the existing evidence of upcoming danger in people with asthma. This review is pivoted on the danger in people with "controlled" acute asthma. It is obvious from some studies that long-term use of corticosteroids cannot stop the progression of asthma and lung damage. The other results show that the adverse effect of the drugs increases even with the lesser dose of oral corticosteroids. So, there is a need for new therapies for the reduction of upcoming risks due to asthma.

Keywords: Asthma, Risk, Severity.
\end{abstract}

\section{INTRODUCTION}

Acute asthma is not a visible disease and is a progressive one. ${ }^{1}$ It cannot be observed by the population as it is invisible. This disease can lead to physical, social, and mental impairment. A lot of patients with asthma have fear and some of them even leave the jobs just due to such fears. Their life is struck due to this problem. They even have issues with their relationships with friends and family. ${ }^{2,3}$ In spite of potent medications, coherence, and adherence, the rate of asthma is not being reduced.

The upcoming severe health problems can be due to the asthmatic burdens. Severe asthma can lead to dangerous exacerbation and damage of pulmonary function. It can also affect medication-related problems for example steroids. Thus, the American Thoracic Society (ATS) guidelines show that asthma requires intense treatment to prevent it from getting uncontrolled. According to the European Respiratory Society (ERS), asthma is not the kind of disease that can be controlled by intense drug procedures ${ }^{4}$.

In routine practice, the risk of asthma is not easily detectable. The present tools for the measurement and diagnosis of asthma and asthma-related morbidity cannot surely predict the upcoming risks of morbidity due to medication. This review is pivoted on the danger in people with "controlled" acute asthma. It is obvious from some studies that long-term use of corticosteroids cannot stop the progression of asthma and lung damage. This review initiates with the question as to the future risks of acute asthma and the importance of its review. This review is based on patients with controlled acute asthma.

Asthma Progression: Diagnosis and Risk Assessment: The idea of the severity of asthma has progressed in the last few years. The feature severity is based on the three main factors, which are the airflow barrier, its exacerbations, and its symptoms. The Global Initiative for Asthma (GINA) guidelines represented the scales to

Received on 05-01-2021

Accepted on 25-03-2021 measure the after-treatment control of asthmatic patients which are as under:

- Intermittent

- Mild Persistent

- Moderate Persistent

- $\quad$ Severe Persistent ${ }^{6}$

This categorization was utilized by physicians and pharmacists to treat the starting therapy for asthma. But, now the present treatments do not consider the previous treatment but focus on the patient and disease control regardless the without treatment therapy ${ }^{7}$.

Nowadays the severity of asthma is based on the intensity of treatment. It is the type of treatment that helps in the achievement of best treatment outcomes for symptoms, obstruction, and exacerbations ${ }^{4}$.

It is vital to understand that any of the asthmatic control tools for example asthma control questionnaire (ACQ) and asthma control test (ACT) do not focus on the future risks of asthma; however, it is the area of concern of my article ${ }^{5}$.

Epidemiology of Asthma: Among articles, the variance of prevalence and definition of acute asthma is caused by the emerging concepts of asthmatic severity. In an experimental study, the data collected from statistical surveillance in the Netherlands, it was evaluated that 3.7\% of asthmatic adults came across acute refractory asthma explicated high-intensity treatment ${ }^{9}$ required to overcome. Poor control and good coherence and inhaler process are the main grounds for it. The existence of acute asthmatics being $1 \%$ among asthmatic adults in the community was proposed by the dominance of this asthma being surged from $3.7 \%$ to $4.6 \%$ when using the ERS/ATS suggestion definition.

In population-based research in Swedish, 750 patients with asthma, showed $37 \%$ asthmatic patients had just signs of severity, for example, 1) multiple symptoms at day time in spite of the utilization of medicines, 2) the FEV1 of lower than $70 \%, 3$ ) daily use of emergency medicine, 4) once in a week nocturnal symptoms and 5) steroids usage $^{10}$. Asthma also existed in the general population. 
In the epidemiological systematic review, a load of acute asthma in the asthmatic population varied extremely from $0.8 \%$ to $50 \%{ }^{11}$. In 1-year longitudinal evaluation study, a lack of control was seen to be continued for a long duration ${ }^{12}$.

Correlation between Bad Asthma and Acute Asthma: Risk Identification and Management: It is noted that people suffering from acute asthma encounter bad control ${ }^{13-19}$. In the natural and epidemiological history of Asthma: Treatment and outcome Regimens (TENOR) 2 Study based on cohort analysis, and evaluation of 340 patients after being registered in TENOR 1 Study, half of the patients had no positive result for control and just $10 \%$ of them showed good control ${ }^{19}$.

The correlation of present control of asthma to upcoming medical results has been continually shown in the published articles. In the TENOR 1 study, the acute continual asthma disease which was more than half of the proportion, the score of controlling asthma represented a quite considerable interrelation with the quality of life at longitudinal and baseline measures ${ }^{20}$.

Along with the above data, the management status of asthma was directly related to oral corticosteroid therapy, hospitalizations, emergency department visits, and unplanned visits to clinics. ${ }^{21}$ The mentioned correlations were managed for the off-treatment asthma complexity ${ }^{20,21}$.

In the initial post hoc evaluation of RCT with the alpha antagonist of the IL-4 receptor, in a population with intermittent to acute atopic asthma, an elevation by $50 \%$ in the upcoming severity of symptoms showed the elevation of 1 score of ACQ score ${ }^{22}$. Along with that, the retrospective evaluation of 5 budesonide/ formoterol reliever and maintenance treatment trials, the present status of control showed the result of $79 \%$ probability and was considerably correlated with upcoming health risks ${ }^{23}$.

In 1 year longitudinal evaluation in the TENOR 1 study, very lower control was considerably attached with upcoming risks of severity ${ }^{24}$.

Upcoming Risks of Severity in Acute Asthmatics: The progression is a key characteristic of acute asthma. It is explained as the aggression of disease needing the utilization of systematic corticosteroids or elevation of its dose continuously until the maintenance dose is achieved $^{25}$.

In an evaluation of TENOR 2 cohort patients, who had complex asthma, $47 \%$ of the patients suffer the enhanced complexity in the present 1 year and $22 \%$ of them suffered from severity at that time. The severity includes the visits to emergency departments as well as the hospitalization due to bad conditions. ${ }^{19}$

In a Web-based database, done in Australia, acute asthmatic people suffered from attack in the next 2 years of the understudied period ${ }^{26}$.

In a long five-annum longitudinal evaluation on the prospective basis, 180 people were studied who had "problematic asthma." Problematic asthma is defined as patients having both acute as well as difficult to treat asthma. The study was conducted in the Singapore population. The results showed three variant scenarios in the form of acute asthma exacerbation values per unit time. The scenarios are as follows:
Infrequent exacerbations: it constituted $60 \%$ steady disease with very less intermittent acute asthma. Nonpersistent frequent exacerbation: it makes about 33\% continual acute asthmatic attacks along at normal range, however, the condition improved with time.

Persistent frequent exacerbation: it constitutes the 5\% of patients, who experienced continuous acute attacks time to time ${ }^{17}$.

The most serious and undesirable class was those persons who suffered from severe asthma attacks twice a year. But with good luck, those were just 5 persons of all. Another two undesirable groups showed a positive result of having just one attack in the next five years.

The undesirable group features consist of a greater body mass index, frequent asthmatic attacks which could be fatal. These also include the continual GERD, sleep problem known as apnoea as well as mood swings as compared to the other classes under observation ${ }^{17}$. To conclude, the presence of complexity and severity represented the upcoming risks due to asthma $26,28-34$. Different factors of patients are as under nasal polyps, comorbid re depression, obesity, smoking, GERD, poor lung working, autoimmune disease are all linked with the coming risks of asthmatic attack in different age and severity population $26,34-41$. The patients with acute asthma along with untreated type 2 pulmonary inflammation are considerably involved in the high rates of complexity and severity of asthma in future ${ }^{42-45}$.

Future Challenges to Pulmonary Functions in Extreme Asthmatic Patients: Just a few research data have evaluated the longitudinal variation in the working of pulmonic tissues of an asthmatic patient. In an evaluation that took 6 years of study, 100 people with acute asthma in the Glen field cohort, the total finding was an annual drop of "after bronchodilator consumption" FEV1 -25mL/annum. There were three groups; these groups were different based on "eosinophilic airway inflammation" and FEV1 reduction rate after using bronchodilators. In these groups, the group with less but present sputum (geometric average eosinophil percentage, $5.27 \%$ with the $95 \%$, confidence interval of $1.09 \%-8.49 \%$ ), and the groups with extreme distinction rate expressed the highest changes in the reduction of pulmonary function. This reduction was approximate -41 millilitre per annum.

The lengthwise course of pulmonary function was analyzed for a duration of ten years in the initial retrospective evaluation of 55 patients living in Japan with e asthma according to the ATS criteria for recurrent asthma $^{47,48}$. The average per day corticosteroid dose was 1800 microgram of beclomethasone dipropionate equal to the average oral corticosteroid utilization period was $68 \pm 62$ days per annum and the yearly severity rate was $0.50 \pm 0.5$. the physical features were showed in that research based on speed in the pulmonary working reduction, fast which includes $(n=18)$ and slow which includes $(n=36)$, pivoted on the FVC, forced vital capacity reduction rate of $-20 \mathrm{~mL}$ per annum. The yearly complexity rate, use of corticosteroids, and age were combined with the fast FVC reduction in cohort study done in Japan. The interaction in the decline of pulmonary function and asthma status was not shown in detail. 
In a longitudinal study for 8 years of 230 people with acute asthma from an unbiased region in Brazil, the average per annum decline in FEV1 was calculated after taking the bronchodilators which were -28 milliliters per year ${ }^{49}$.

The Upcoming Risks of Corticosteroids Tempted Disease in Complex Asthmatics: It is found out that normal people take systematic corticosteroid therapy any time for asthma or other conditions includes about $1 \%$. It is about $30 \%$ of the prescriptions ${ }^{50-52}$.

It is well understood that the utilization of systematic corticosteroids with the high risk of psychiatric occasions, infection, fracture, and gastric problems ${ }^{53,54}$.

The patients who received large doses of a drug, for example, more than 6 milligrams per day had considerably greater complications which include ocular, bone, gastrointestinal, metabolic, and cardiovascular problems along with infections.

In the other research that used the organizational claims data evaluation of complex asthma patients and controls. The complexity of progressing systematic corticosteroidassociated severities enhanced considerably in a dosedependent way. Even the patients with a low dose of such drugs which is lower than 5 milligrams per day of prednisolone, showed elevated risks of severity as compared to those patients who did not take medications especially the steroids (OR, 3 and confidence interval 1.35.0 for $95 \%$ ).

Risks of Mortality in Acute Asthmatics: Death ratio has significantly declined in the recent years through asthma which is due to the positive outcomes of ICS therapy. However, the risk hasn't completely vanished and it still exists in patients with acute asthmatics. A recent study of 20 years follow up observation of 50 patients (age baseline: $49 \pm 18.9$ years) with severe asthma in France has shown that, their mortality rate was $50 \%$, out of which $19 \%$ was contributed by fatal asthma. The relative survival ratio was about 0.78 . These results indicated the excessive death rate of $22 \%$ in acute asthmatic people. Another study, that involved 3 years of longitudinal follow up period of acute asthematic patients showed that in those 3 years, the death ratio was higher in acute asthmatics as compared to nonasthmatic controlled population ( $7 \%$ vs $5 \%$; $P=0.007)$. In a meta-analysis of nested controlled case of severe asthmatic population in Brazil, 59 deaths and 233 nonmortality cases, at $1: 4$ ratio, was observed. $60 \%$ of the deaths were due to respiratory issues. In this study, poor asthma handling and lower pre-bronchodilator FEV1 $<60 \%$ of the cases showed higher death rate, especially the males ${ }^{55}$.

Concerns Regarding Controlled State of Severe Asthma: As discussed before, the risks linked with the severe asthmatic condition of patients have not been studied and researched completely. The data based upon trials and observations is limited. These patients are often confined to grey zone categories because owing to their declining health condition, their future health state is unpredictable. For these reasons, a question and huge concern exist that is controlled severe asthma completely handled and controlled for real? the answer here, is negative because of the side effects of drugs used for its management and the future risk they hold. Even with low dose administration and SCS exposure, these drugs still hold side effects. Moreover, it is predicted that future asthma progression cannot be avoided by chronic corticosteroid therapy. Even with high intensity treatments in patients, who showed improvement in their asthmatic condition with therapy, lungs' functional decline still wasn't prevented.

Based upon the side effects observed by the usage of medicines for asthma, the dire need for novel drugs exists which will be able to taper the OCS use by keeping asthma in control and under check. In this niche, some therapies that are T-2 targeted biological in nature like antibodies targeting IL-4 and IL-5 pathways have proved effective in patients who were OCS dependent with acute asthma. These therapies succeeded in the reduction of OCS dose maintenance. Despite the effectiveness of these therapies with OCS-sparing perk, these drugs were still not $100 \%$ efficient when it came to absolute responses in comparison to placebo. In a placebo managed study of trial of 140 patients with acute esosinophilic asthma depend upon OCS (with median daily dose of $12.5-13 \mathrm{mg}$ of prednisone in treatment group), from baseline a range of $20 \%$ to $75 \%$ with median reduction of OCS dose by up to $50 \%$ was observed in mepolizumab treated group. These results were compared to $0 \%$ in the placebo group where the reduction range was 20 to $30 \%$. In the group of mepolizumab, $54 \%$ decline in daily OCS to a level of $\leq 5$ mg was observed; whereas in placebo group this percentage was $32 \%$. In another study of 28 weeks of RCT, 230 patients were added who were facing severe esoinophilic asthma with OCS dependency. Their mean daily OCS dose was: $10 \mathrm{mg}$ of predinosolone. In comparison to placebo, study showed the OR of OCS dose decline at 4.12 rate with benralizumab. This reduction, at the final visit became $5 \mathrm{mg}$ of OCS dose in benralizumab therapy group (observed every 8 week), and the OCS dose was $10 \mathrm{mg}$ in the placebo group ${ }^{56}$.

In these trials, risk reduction was observed within the range of $33 \%$ to $71 \%$ through the use of T-2 targeted biological therapeutic compounds, where exacerbation rates were present in these trials. However, exacerbation still existed. In placebo group, the yearly exacerbation rate was 2.13 in placebo group, on the other hand, in mepolizumab group this yearly exacerbation rate was 1.44 . In the benralizumab therapeutic group, the ratio was observed as 0.54 / year, while in placebo it was 1.83; and in dupilumab it was 0.65 where as in the placebo group this ratio was found as 1.60 . The mean betterment in the ACQ values was credited due to biological therapeutic drugs ranged between -0.52 and -0.47 (all statistically significant in comparison to placebo). Contrarily, the impact of these biologics was dwindling on pre-bronchodilator FEV1 with inconsistent significance.

The long term impacts of these biological drugs are unknown because the follow up study was only of 1 year. Over a period of 4 year, positive effects were observed on the reduction of exacerbation by mepolizumab, but it wasn't successful in the prevention of annual decline in FEV1. However, no placebo controlled group was present to develop a comparative study which might would have aided in investigation that the failure of preventing the decline in FEV1 was the inability of mepolizumab to handle the 
upcoming risks of lung's functional deterioration in severe asthmatics.

In the nut shell, T-2 targeted biological compounds proved effective in declining the risk of exacerbations, specifically for corticosteroid based asthamtics along with the reduction in dose dependency of OCS. Further progress can only be achieved by more deep study about T-2 targeted compounds and their associated mechanisms that can interfere in the future risks, mentioned above, in severe asthmatic patients.

\section{CONCLUSION}

Acute asthmatic condition is life threatening. This condition not only directly impact daily life, but it can also impact the long term future health outcomes. However, the health risks associated with this health severity is poorly understood and measured by patients and their physician which has only worsened the situation. The drugs used for high intensity treatment are administered in patients for handling asthma activity, but these drugs are not free from adverse side effects. Such high potency drugs are given to patients who have severe asthma, thus side effects add fuel to fire and further decline patient's health. Surprisingly, even with the administration of low doses of OCS, side effects and OCS induced complications were still found in patients. In addition to these complications, it is also not known that either the use of OCS for long term is helpful in prevention of asthma progression in future or not. Thus, controlled acute asthma is not as completely controlled as it once seemed. On the other hand, T-2 targeted biological compounds (newly developed) proved helpful in declining the daily dependency dose of OCS, reducing the exacerbation risks and improving health status in OCSdependent severe asthmatic patients. However, their long term benefits are still under study. These findings depict that there is a gap of clinical needs for patients with severe asthma, which exists even under high intensity treatments. Further research and deep study can aid in finding more good clinical options for the management of severe asthmatic patients which can also reduce their future adverse health outcomes.

\section{REFERENCE}

1. Wenzel SE, Brillhart S, Nowack K. An invisible disease: severe asthma is more than just "bad asthma". Eur Respir $\mathrm{J}$ 2017;50:1701109

2. Foster JM, McDonald VM, Guo M, Reddel HK. "I have lost in every facet of my life": the hidden burden of severe asthma. Eur Respir J 2017;50:1700765

3. Eassey D, Reddel HK, Foster JM, Kirkpatrick S, Locock L, Ryan K, et al. "...I've said I wish I was dead, you'd be better off without me": a systematic review of people's experiences of living with severe asthma. J Asthma 2019;56:311-322.

4. Chung KF, Wenzel SE, Brozek JL, Bush A, Castro M, Sterk PJ, et al. International ERS/ATS guidelines on definition, evaluation and treatment of severe asthma. Eur Respir $\mathrm{J}$ 2014;43:343-373.

5. Hyland ME, Whalley B, Jones RC, Masoli M. A qualitative study of the impact of severe asthma and its treatment showing that treatment burden is neglected in existing asthma assessment scales. Qual Life Res 2015;24:631-639.
6. Taylor DR, Bateman ED, Boulet LP, Boushey HA, Busse WW, Casale TB, et al. A new perspective on concepts of asthma severity and control. Eur Respir J 2008;32:545-554.

7. Bateman ED, Bousquet J, Braunstein GL. Is overall asthma control being achieved? A hypothesis-generating study. Eur Respir J 2001;17:589-595.

8. Papaioannou AI, Kostikas K, Zervas E, Kolilekas L, Papiris S, Gaga M. Control of asthma in real life: still a valuable goal? Eur Respir Rev 2015;24:361-369.

9. Hekking PP, Wener RR, Amelink M, Zwinderman AH, Bouvy $\mathrm{ML}, \mathrm{Bel} \mathrm{EH}$. The prevalence of severe refractory asthma. J Allergy Clin Immunol 2015;135:896-902.

10. Mincheva R, Ekerljung L, Bossios A, Lundbäck B, Lötvall J. High prevalence of severe asthma in a large random population study. J Allergy Clin Immunol 2018;141:22562264.e2.

11. Chen S, Golam S, Myers J, Bly C, Smolen H, Xu X. Systematic literature review of the clinical, humanistic, and economic burden associated with asthma uncontrolled by GINA Steps 4 or 5 treatment. Curr Med Res Opin 2018;34:2075-2088.

12. Silkoff PE, Laviolette M, Singh D, FitzGerald JM, Kelsen S, Backer V, et al. Longitudinal stability of asthma characteristics and biomarkers from the Airways Disease Endotyping for Personalized Therapeutics (ADEPT) study. Respir Res 2016;17:43.

13. Kim MH, Kim SH, Park SY, Ban GY, Kim JH, Jung JW, et al. Characteristics of adult severe refractory asthma in Korea analyzed from the severe asthma registry. Allergy Asthma Immunol Res 2019;11:43-54.

14. Hermosa JL, Sánchez CB, Rubio MC, Mínguez MM, Walther $\mathrm{JL}$. Factors associated with the control of severe asthma. J Asthma 2010;47:124-130.

15. Díez JM, Barcina C, Muñoz M, Leal M. Control of persistent asthma in Spain: associated factors. J Asthma 2008;45:740746.

16. Turktas H, Mungan D, Uysal MA, Oguzulgen K. Turkish Asthma Control Survey Study Group. Determinants of asthma control in tertiary level in Turkey: a cross-sectional multicenter survey. J Asthma 2010;47:557-562.

17. Yii AC, Tan JH, Lapperre TS, Chan AK, Low SY, Ong TH, et al. Long-term future risk of severe exacerbations: distinct 5year trajectories of problematic asthma. Allergy 2017;72:1398-1405.

18. Magnoni MS, Latorre M, Bettoncelli G, Sanchez-Herrero MG, Lopez A, Calvo E, et al. Asthma control in primary care: the results of an observational cross-sectional study in Italy and Spain. World Allergy Organ J 2017;10:13.

19. Chipps BE, Haselkorn T, Paknis B, Ortiz B, Bleecker ER, Kianifard $F$, et al. More than a decade follow-up in patients with severe or difficult-to-treat asthma: The Epidemiology and Natural History of Asthma: Outcomes and Treatment Regimens (TENOR) II. J Allergy Clin Immunol 2018;141:1590-1597.e9.

20. Chen H, Gould MK, Blanc PD, Miller DP, Kamath TV, Lee JH, et al. Asthma control, severity, and quality of life: quantifying the effect of uncontrolled disease. J Allergy Clin Immunol 2007;120:396-402.

21. Sullivan SD, Wenzel SE, Bresnahan BW, Zheng B, Lee JH, Pritchard $\mathrm{M}$, et al. Association of control and risk of severe asthma-related events in severe or difficult-to-treat asthma patients. Allergy 2007;62:655-660.

22. Meltzer EO, Busse WW, Wenzel SE, Belozeroff $\mathrm{V}$, Weng HH, Feng J, et al. Use of the Asthma Control Questionnaire to predict future risk of asthma exacerbation. J Allergy Clin Immunol 2011;127:167-172.

23. Bateman ED, Reddel HK, Eriksson G, Peterson S, Östlund O, Sears MR, et al. Overall asthma control: the relationship between current control and future risk. J Allergy Clin Immunol 2010;125:600-608. 608.e1-606. 
24. Haselkorn T, Fish JE, Zeiger RS, Szefler SJ, Miller DP, Chipps BE, et al. Consistently very poorly controlled asthma, as defined by the impairment domain of the Expert Panel Report 3 guidelines, increases risk for future severe asthma exacerbations in The Epidemiology and Natural History of Asthma: Outcomes and Treatment Regimens (TENOR) study. J Allergy Clin Immunol 2009;124:895-902.e1-

25. Fuhlbrigge A, Peden D, Apter AJ, Boushey HA, Camargo CA $\mathrm{Jr}$, Gern J, et al. Asthma outcomes: exacerbations. J Allergy Clin Immunol 2012;129:S34-4

26. McDonald VM, Hiles SA, Godbout K, Harvey ES, Marks GB, Hew M, et al. Treatable traits can be identified in a severe asthma registry and predict future exacerbations. Respirology 2019;24:37-47.

27. Bel EH, Sousa A, Fleming L, Bush A, Chung KF, Versnel J, et al. Diagnosis and definition of severe refractory asthma: an international consensus statement from the Innovative Medicine Initiative (IMI). Thorax 2011;66:910-917.

28. Miller MK, Lee JH, Miller DP, Wenzel SE. TENOR Study Group. Recent asthma exacerbations: a key predictor of future exacerbations. Respir Med 2007;101:481-489.

29. Calhoun WJ, Haselkorn T, Mink DR, Miller DP, Dorenbaum A, Zeiger RS. Clinical burden and predictors of asthma exacerbations in patients on guideline-based steps 4-6 asthma therapy in the TENOR cohort. J Allergy Clin Immunol Pract 2014;2:193-200.

30. Tanaka A, Uno $T$, Sato $H$, Jinno M, Hirai $K$, Miyata $Y$, et al. Predicting future risk of exacerbations in Japanese patients with adult asthma: a prospective 1-year follow up study. Allergol Int 2017;66:568-573.

31. Kang HR, Song HJ, Nam JH, Hong SH, Yang SY, Ju S, et al. Risk factors of asthma exacerbation based on asthma severity: a nationwide population-based observational study in South Korea. BMJ Open 2018;8:e020825

32. Boer S, Sont JK, Loijmans RJ, Snoeck-Stroband JB, ter Riet G, Schermer TR, et al. Development and validation of personalized prediction to estimate future risk of severe exacerbations and uncontrolled asthma in patients with asthma, using clinical parameters and early treatment response. J Allergy Clin Immunol Pract 2019;7:175-182.e5.

33. Bloom Cl, Palmer $\mathrm{T}$, Feary $\mathrm{J}$, Quint $\mathrm{JK}$, Cullinan $\mathrm{P}$ Exacerbation patterns in adults with asthma in England. a population-based study. Am J Respir Crit Care Med 2019;199:446-453.

34. Patel M, Pilcher J, Reddel HK, Qi V, Mackey B, Tranquilino T, et al. Predictors of severe exacerbations, poor asthma control, and $\beta$-agonist overuse for patients with asthma. $\mathrm{J}$ Allergy Clin Immunol Pract 2014;2:751-758.

35. Loymans RJ, Honkoop PJ, Termeer EH, Snoeck-Stroband JB, Assendelft WJ, Schermer TR, et al. Identifying patients at risk for severe exacerbations of asthma: development and external validation of a multivariable prediction model. Thorax 2016;71:838-846.

36. Park HW, Song WJ, Kim SH, Park HK, Kim SH, Kwon YE, et al. Classification and implementation of asthma phenotypes in elderly patients. Ann Allergy Asthma Immunol 2015;114:1822.

37. Bateman ED, Buhl R, O'Byrne PM, Humbert M, Reddel HK, Sears MR, et al. Development and validation of a novel risk score for asthma exacerbations: the risk score for exacerbations. J Allergy Clin Immunol 2015;135:14571464.e4.

38. Kupczyk M, ten Brinke A, Sterk PJ, Bel EH, Papi A, Chanez $P$, et al. Frequent exacerbators--a distinct phenotype of severe asthma. Clin Exp Allergy 2014;44:212-221.
39. Song WJ, Sintobin I, Sohn KH, Kang MG, Park HK, Jo EJ, et al. Staphylococcal enterotoxin IgE sensitization in late-onset severe eosinophilic asthma in the elderly. Clin Exp Allergy 2016;46:411-421.

40. Bloom Cl, Nissen F, Douglas IJ, Smeeth L, Cullinan P, Quint JK. Exacerbation risk and characterisation of the UK's asthma population from infants to old age. Thorax 2018;73:313-320.

41. Mukherjee $M$, Nair $P$. Autoimmune responses in severe asthma. Allergy Asthma Immunol Res 2018;10:428-447.

42. Pavord ID, Korn S, Howarth P, Bleecker ER, Buhl R, Keene $\mathrm{ON}$, et al. Mepolizumab for severe eosinophilic asthma (DREAM): a multicentre, double-blind, placebo-controlled trial. Lancet 2012;380:651-659.

43. Ortega HG, Yancey SW, Mayer B, Gunsoy NB, Keene ON Bleecker ER, et al. Severe eosinophilic asthma treated with mepolizumab stratified by baseline eosinophil thresholds: a secondary analysis of the DREAM and MENSA studies. Lancet Respir Med 2016;4:549-556.

44. Hanania NA, Wenzel S, Rosén K, Hsieh HJ, Mosesova S, Choy DF, et al. Exploring the effects of omalizumab in allergic asthma: an analysis of biomarkers in the EXTRA study. Am J Respir Crit Care Med 2013;187:804-811.

45. Wenzel S, Swanson B, Teper A, Hamilton J, Izuhara K, Ohta $S$, et al. Dupilumab reduces severe exacerbations in periostin-high and periostin-low asthma patients. Eur Respir J 2016;48:OA1798

46. Newby C, Agbetile J, Hargadon B, Monteiro W, Green R, Pavord I, et al. Lung function decline and variable airway inflammatory pattern: longitudinal analysis of severe asthma. J Allergy Clin Immunol 2014;134:287-294.

47. American Thoracic Society. Proceedings of the ATS workshop on refractory asthma: current understanding, recommendations, and unanswered questions. Am J Respir Crit Care Med 2000;162:2341-2351.

48. Matsunaga K, Akamatsu K, Miyatake A, Ichinose M. Natural history and risk factors of obstructive changes over a 10-year period in severe asthma. Respir Med 2013;107:355-360.

49. Almeida PC, Ponte EV, Souza-Machado A, Cruz AA. Longitudinal trends in clinical characteristics and lung function of patients with severe asthma under treatment in Brazil. BMC Pulm Med 2016;16:141.

50. Fardet L, Petersen I, Nazareth I. Prevalence of long-term oral glucocorticoid prescriptions in the UK over the past 20 years. Rheumatology (Oxford) 2011;50:1982-1990.

51. van Staa TP, Leufkens HG, Abenhaim L, Begaud B, Zhang B, Cooper C. Use of oral corticosteroids in the United Kingdom. QJM 2000;93:105-111.

52. Overman RA, Yeh JY, Deal CL. Prevalence of oral glucocorticoid usage in the United States: a general population perspective. Arthritis Care Res (Hoboken) 2013;65:294-298.

53. Sarnes E, Crofford L, Watson M, Dennis G, Kan H, Bass D. Incidence and US costs of corticosteroid-associated adverse events: a systematic literature review. Clin Ther 2011;33:1413-1432.

54. Rice JB, White AG, Scarpati LM, Wan G, Nelson WW. Longterm systemic corticosteroid exposure: a systematic literature review. Clin Ther 2017;39:2216-2229.

55. Fernandes AG, Souza-Machado C, Coelho RC, Franco PA, Esquivel RM, Souza-Machado A, et al. Risk factors for death in patients with severe asthma. $J$ Bras Pneumol 2014;40:364-372.

56. Nair P, Wenzel S, Rabe KF, Bourdin A, Lugogo NL, Kuna P, et al. Oral glucocorticoid-sparing effect of benralizumab in severe asthma. N Engl J Med 2017;376:2448-2458. 